\title{
Correction to: RNA G-quadruplexes at upstream open reading frames cause DHX36- and DHX9-dependent translation of human mRNAs
}

Pierre Murat ${ }^{1,2}$, Giovanni Marsico ${ }^{2}$, Barbara Herdy ${ }^{2}$, Avazeh T. Ghanbarian ${ }^{2,3}$, Guillem Portella ${ }^{1}$ and Shankar Balasubramanian ${ }^{1,2,4^{*}}$

\section{Correction to: Genome Biol}

https://doi.org/10.1186/s13059-018-1602-2

Following publication of the original article [1], the authors reported the following error in the name of the fourth author.

Incorrect author name: Avazeh Ghanbarian

Correct author name: Avazeh T. Ghanbarian

Avazeh T. Ghanbarian is affiliated with 'European Bioinformatics Institute (EMBL-EBI), Hinxton, Cambridge, UK, CB10 1SD'.

\footnotetext{
Author details

'Department of Chemistry, University of Cambridge, Lensfield Road, Cambridge CB2 1EW, UK. ${ }^{2}$ Cancer Research UK Cambridge Institute, University of Cambridge, Li Ka Shing Centre, Robinson Way, Cambridge CB2 ORE, UK. ${ }^{3}$ European Bioinformatics Institute (EMBL-EBI), Hinxton, Cambridge CB10 1SD, UK. ${ }^{4}$ School of Clinical Medicine, University of Cambridge, Cambridge CB2 OSP, UK
}

Received: 2 January 2019 Accepted: 4 January 2019

Published online: 11 January 2019

\section{Reference}

1. Murat, et al. RNA G-quadruplexes at upstream open reading frames cause DHX36- and DHX9-dependent translation of human mRNAs. Genome Biol. 2018;19:229. https://doi.org/10.1186/s13059-018-1602-2.

\footnotetext{
* Correspondence: sb10031@cam.ac.uk

'Department of Chemistry, University of Cambridge, Lensfield Road, Cambridge CB2 1EW, UK

${ }^{2}$ Cancer Research UK Cambridge Institute, University of Cambridge, Li Ka

Shing Centre, Robinson Way, Cambridge CB2 ORE, UK

Full list of author information is available at the end of the article
}

(c) The Author(s). 2019 Open Access This article is distributed under the terms of the Creative Commons Attribution 4.0 International License (http://creativecommons.org/licenses/by/4.0/), which permits unrestricted use, distribution, and reproduction in any medium, provided you give appropriate credit to the original author(s) and the source, provide a link to the Creative Commons license, and indicate if changes were made. The Creative Commons Public Domain Dedication waiver (http://creativecommons.org/publicdomain/zero/1.0/) applies to the data made available in this article, unless otherwise stated. 